\title{
INTERNATIONAL INSTITUTE FOR DEMOCRACY AND ELECTORAL ASSISTANCE (IDEA)
}

Created in 1995, the International IDEA is an intergovernmental organization that seeks to promote and develop sustainable democracy worldwide. Global in membership and independent of specific national interests, IDEA works with both new and long-established democracies, helping to develop the institutions and culture of democracy. It operates at international, regional and national levels, working in partnership with a range of institutions.

Aims and Activities. The International IDEA aims to: help countries build capacity to develop democratic institutions; provide a meeting-place for and facilitate dialogue between democracy practitioners around the world; increase knowledge and expertise about elections and election observation; promote transparency, accountability, professionalism and efficiency in elections in the context of democratic development; develop and promote norms, rules and guidelines relating to multi-party pluralism and broader democratic processes. The principal areas of activity include: electoral systems and management; political participation, including women in politics; political parties, management and financing; postconflict democracy building and reconciliation; democracy at local level; democracy indicators and assessment.

Membership. The International IDEA had 21 members in March 2004.

Headquarters: Strömsberg, 10334 Stockholm, Sweden.

Website: http://www.idea.int

Secretary-General: Karen Fogg (UK).

\section{ORGANIZATION OF THE ISLAMIC CONFERENCE (OIC)}

Founded in 1969, the objectives of the OIC are to promote Islamic solidarity among member states; to consolidate co-operation among member states in the economic, social, cultural, scientific and other vital fields of activities, and to carry out consultations among member states in international organizations; to endeavour to eliminate racial segregation, discrimination and to eradicate colonialism in all its forms; to take the necessary measures to support international peace and security founded on justice; to strengthen the struggle of all Muslim peoples with a view to safeguarding their dignity, independence and national rights; to create a suitable atmosphere for the promotion of co-operation and understanding among member states and other countries.

Members (57 as of March 2004). Afghanistan, Albania, Algeria, Azerbaijan, Bahrain, Bangladesh, Benin, Brunei, Burkina Faso, Cameroon, Chad, Comoros, Côte d'Ivoire, Djibouti, Egypt, Gabon, The Gambia, Guinea, Guinea-Bissau, Guyana, Indonesia, Iran, Iraq, Jordan, Kazakhstan, Kuwait, Kyrgyzstan, Lebanon, Libya, Malaysia, Maldives, Mali, Mauritania, Morocco, Mozambique, Niger, Nigeria, Oman, Pakistan, Palestine, Qatar, Saudi Arabia, Senegal, Sierra Leone, Somalia, Sudan, Suriname, Syria, Tajikistan, Togo, Tunisia, Turkey, Turkmenistan, Uganda, United Arab Emirates, Uzbekistan, Yemen. Observer states: BosniaHerzegovina, Central African Republic, Thailand.

Headquarters: PO Box 5925, Jeddah, Saudi Arabia.

Website: http://www.oic-un.org

Secretary-General: Dr Abdelouahed Belkeziz (Morocco). 